\title{
Propuesta de justificación del programa de licenciatura en matemáticas
}

\author{
HERNANDO GUTIÉRREZ HOYOS*
}

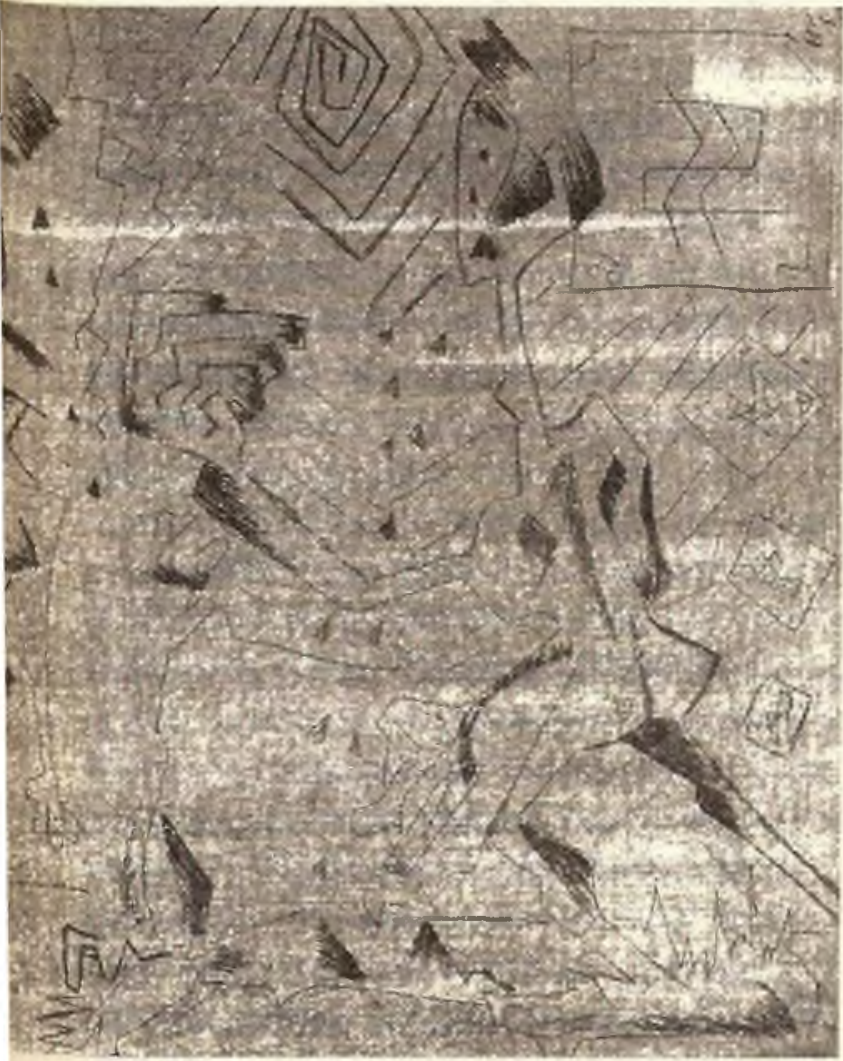

Ilustración: Diana Yamile Olarte

- Profesor titular de la Universidad Surcolombiana, en el programa de Matemáticas.
7 a obligatoria necesidad, como condición de supervivencia, que tiene nuestro país de asumir los diferentes procesos de globalización característicos del mundo actual exige una "toma colectiva de conciencia" que comprometa tanto a gobernantes, dirigentes políticos y líderes empresariales como a todos los ciudadanos del común.

No se trata, únicamente, de prepararnos para "aprender" a "manipular" u "operar" la múltiple, y cada vez más compleja, variedad de implementos producidos por la tecnología moderna que nos llegan a través de las multinacionales en busca de nuestros mercados, materias primas y mano de obra barata.

Tampoco se trata de lanzarnos, ciegamente, a una descarnada y voraz competencia, caracterizada por la más absoluta deshumanización, en la cual se impongan como únicos requisitos para la supervivencia "la ley del más fuerte" o las "leyes de la astucia y la audacia".

Se trata de afianzarnos como nación en el contexto internacional acreditan- 
Universidad SURColombiana

do los resultados culturales al igual que flexibilizando las fronteras a los intercambios científicos, tecnológicos, económicos, políticos, sociales y culturales sobre la base del respeto mutuo a la soberanía y autonomía de cada nación, y teniendo en cuenta que el objetivo principal de este esfuerzo deber ser la búsqueda del bienestar material y espiritual de todos los ciudadanos del país como prerrequisito para lograr un desarrollo integral y sostenible que se corresponda con nuestra condición de seres humanos.

Para intentar estas metas es perentorio e impostergable la introducción de cambios y ajustes, algunos de ellos seguramente radicales, en todos los diferentes sistemas que integran la estructura orgánica de nuestra sociedad.

El sistema educativo, por ejemplo, responsable de la formación y preparación de los recursos humanos con los cuales se pueda afrontar confiadamente estos retos aperturistas e integracionistas, debe adecuarse, como el que más, a los vertiginosos avances científicos, técnicos y tecnológicos alcanzados en el campo de la teleinformática al igual que a la experimentación de las nuevas metodologías que se proponen como alternativas modernas en el proceso enseñanza aprendizaje asumiéndolas, tanto a tecnologías como a metodologías, más como medios para cualificar los procesos de enseñanza que como fines de la educación.

Este ultimátum de modernización o actualización que debe acatar el sistema educativo colombiano, tendrá que cobijar, necesariamente, al proceso de formación de educadores o docentes al cual, prácticamente corresponden las tareas de oxigenar y regenerar el teji- do social, pues, ellos deberán encargarse de la formación y capacitación de los niños y los jóvenes que se integran como células nuevas para renovar y revitalizar el organismo social desde los diferentes frentes para las cuales se preparen.

En el caso específico de la formación de docentes para la enseñanza de la matemática en los niveles básicos de la educación primaria y secundaria el reto que se nos plantea en los actuales momentos es notoriamente complejo y difícil de asumir.

En efecto, si bien es cierto que nadie se atrevería a cuestionar la importancia y el significado que las matemáticas tienen para fundamentar el desarrollo científico, técnico, tecnológico e industrial de un país; también lo es que muy pocas personas, demasiado pocas, saben de qué manera se articulan las matemáticas a estos procesos. Inclusive, casi que como una tradición milenaria los programas oficiales de educación incluyen desde muy temprana edad la enseñanza de la matemática, pensándola más como un recurso para promover, orientar y estimular el desarrollo intelectual de los niños y jóvenes que como fuente de métodos para la solución de problemas prácticos asociados a las expectativas del desarrollo de un país. Siempre se ha creído que dadas las características del proceso de formación del conocimiento matemático, se debe implementar la enseñanza de esta disciplina desde muy temprana edad para estimular e inducir el desarrollo intelectual a procesos cognoscitivos de mayor generalidad y complejidad.

Debemos, pues, replantearnos, el papel que juega la matemática en la 
educación actual al igual que la orientación que se le viene dando a su enseñanza e incluso, la vigencia de los contenidos que actualmente se imparten en escuelas, colegios y universidades.

Desde esta perspectiva, y teniendo en cuenta el espíritu y los lineamientos del decreto 272 de 1998, la Facultad de Educación de la Universidad Surcolombiana, a través de su Departamento de Matemáticas, propone un nuevo programa de Licenciatura para atender los requerimientos de la formación matemática de los estudiantes en los niveles primario, secundario y media vocacional.

Este programa se propone la formación de un profesional de la educación con conocimientos especializados en matemática para que oriente los procesos de sensibilización, aproximación, asimilación y formación de los estudiantes de primaria y secundaria en el área de la matemática.

A cambio de formar un transmisor reproductor de técnicas, métodos y fórmulas para calcular algoritmos se pretende generar un portador de aptitudes para afrontar problemas en los cuales más importante que soluciones de los mismos sea el estudio de las condiciones en las que se pueden presentar determinadas soluciones. De igual forma, más que un expositor- recitador de teoremas ajustados a la rigurosa presentación lógica deductiva de la matemática, se requiere formar un conocedor de diferentes procesos cognitivos que pueda detectar las múltiples formas de razonamiento, o lógicas, que empleen los estudiantes al enfrentarse con una situación problemática - y las pueda manejar para encausar el desarrollo de la creatividad.

En todo caso, se propenderá por una visión integral de la matemática de tal manera que las diferentes asignaturas del plan de estudio, pertenecientes al área de formación específica, estén ligadas por ejes temáticos que nos permitan trasegar de las matemáticas a la matemática de tal forma que podamos identificar en la multiplicidad de teorías que denominamos como matemáticas la indisoluble unidad de esta ciencia.

Tratándose, además, de un programa para formar docentes, se incluirá un plan curricular orientado a fomentar una sólida e integral formación humanística. Por ello, todas y cada una de las asignaturas pertinentes del plan estarán centradas en el estudio del hombre como ser biológico, ser espiritual, ser social, no compartimentado ni fraccionado, buscando siempre la reciprocidad entre su desarrollo individual y el desarrollo social. En tal sentido, deberán generarse la formación de aptitudes y actitudes positivas para que el nuevo profesional de la educación con especialidad en Matemática haga suyo, como meta de realización personal, el siguiente principio:

"El conocimiento científico y el conocimiento filosófico hallan su razón de ser en la búsqueda del bienestar colectivo de la sociedad y la garantía del pleno desarrollo de la condición humana para todos y cada uno de los seres humanos que poblamos el planeta tierra". 


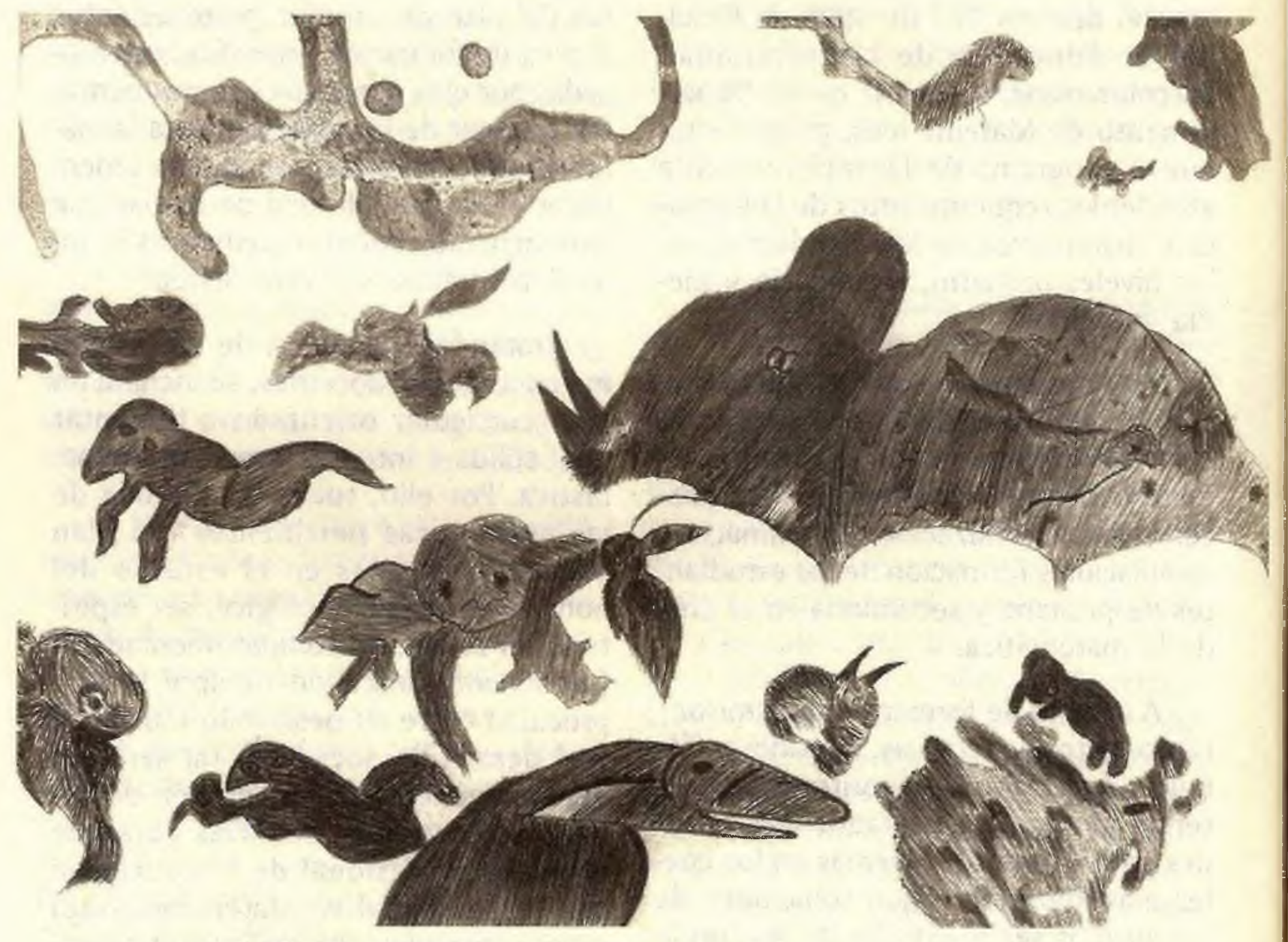

Ilustración: Marco Aurelio Méndez. 